\title{
Biological roles of hepatocyte growth factor-Met signaling from genetically modified animals (Review)
}

\author{
TAKASHI KATO \\ Urologic Oncology Branch, National Cancer Institute, National Institute of Health, Bethesda, MD 20892, USA
}

Received May 10,2017; Accepted September 26, 2017

DOI: 10.3892/br.2017.1001

\begin{abstract}
Hepatocyte growth factor (HGF) is produced by stromal and mesenchymal cells, and it stimulates epithelial cell proliferation, motility, morphogenesis and angiogenesis in various organs via tyrosine phosphorylation of its cognate receptor, Met. The HGF-Met signaling pathway contributes in a paracrine manner to the development of epithelial organs, exerts regenerative effects on the epithelium, and promotes the regression of fibrosis in numerous organs. Additionally, the HGF-Met signaling pathway is correlated with the biology of cancer types, neurons and immunity. In vivo analyses using genetic modification have markedly increased the profound understanding of the HGF-Met system in basic biology and its clinical applications. HGF and Met knockout (KO) mice are embryonically lethal. Therefore, amino acids in multifunctional docking sites of Met have been exchanged with specific binding motifs for downstream adaptor molecules in order to investigate the signaling potential of the HGF-Met signaling pathway. Conditional Met KO mice were generated using Cre-loxP methodology and characterization of these mice indicated that the HGF-Met signaling pathway is essential in
\end{abstract}

Correspondence to: Dr Takashi Kato, Urologic Oncology Branch, National Cancer Institute, National Institute of Health, Center for Cancer Research Building 10, Room 1-5940 Center Drive MSC 1107, Bethesda, MD 20892, USA

E-mail: takashi0920k@gmail.com

Abbreviations: AEC, alveolar epithelial cells; ALS, amyotrophic lateral sclerosis; AR, androgen receptor; ASD, autism spectrum disorder; cKO, conditional knockout; Gab1, Grb2-associated protein 1; Grb2, growth factor receptor-bound protein 2; HE, hyperproliferative epithelium; HGF, hepatocyte growth factor; HLP, HGF-like protein; IPT, immunoglobulin-like regions in plexins and transcription factors; MSP, macrophage stimulating protein; $\mathrm{PH}$, partial hepatectomy; PI3K, phosphoinositide 3-kinase; PSI, plexin, semaphorin, integrin cysteine-rich domain; RIP, rat insulin II promoter; SBMA, spinal and bulbar muscular atrophy; SEMA, semaphorin; SF, scatter factor; Shp2, Src homology region 2 domain-containing phosphatase-2; Stat3, signal transducer and activation of transcription-3; Tg, transgenic

Key words: hepatocyte growth factor, c-Met, regeneration, development, conditional knockout, transgenic mice regeneration, protection, and homeostasis in various tissue types and cells. Furthermore, the results of studies using HGF-overexpressing mice have indicated the therapeutic potential of HGF for various types of disease and injury. In the present review, the phenotypes of Met gene-modified mice are summarized.

\section{Contents}

1. Introduction

2. HGF and Met KO mice

3. Conditional Met KO mice

4. HGF transgenic mice

5. Conclusion

\section{Introduction}

Hepatocyte growth factor (HGF). HGF was cloned as a growth factor for hepatocytes $(1,2)$, is identical to scatter factor (SF) and was originally discovered as a fibroblast-derived cell motility factor for epithelial cells (3). HGF is located at $7 q 21$, which spans $>70 \mathrm{~kb}$ in length and consists of 18 exons. It encodes the inactive pre-pro-HGF, a single chain of 728 amino acids (83 kDa), which includes a signal sequence (1-31), a heavy $\alpha$ chain $(69 \mathrm{kDa})$, and a light $\beta$ chain $(34 \mathrm{kDa})$. The exons encode the $\alpha$ chain, with four kringle structures (highly conserved triple disulfide loop structures), a short spacer region between the $\alpha$ and $\beta$ chains, and the $\beta$ chain (Fig. 1A) (4-6).

HGF is produced and secreted by adjacent stromal and mesenchymal cells, it contributes to the development of epithelial organs in a paracrine fashion, exerts regenerative effects on epithelia in the liver, kidney, lung, and other tissues, and promotes the regression of fibrosis in numerous organs $(7,8)$. Various growth factors, cytokines, and prostaglandins upregulate HGF gene expression, including basic fibroblast growth factor, oncostatin $\mathrm{M}$, hypoxia-inducible factor $1 \alpha$ and nuclear factor- $\kappa \mathrm{B}(\mathrm{NF}-\kappa \mathrm{B})(9)$. By contrast, transforming growth factor (TGF)- $\beta 1$ was demonstrated to markedly downregulate HGF gene expression $(10,11)$.

HGF forms a family with HGF-like protein (HLP), a unique protein with a domain structure similar to that of HGF (12). Macrophage stimulating protein (MSP) was discovered as a serum protein that promoted mouse macrophage motility (13), 
A HGF

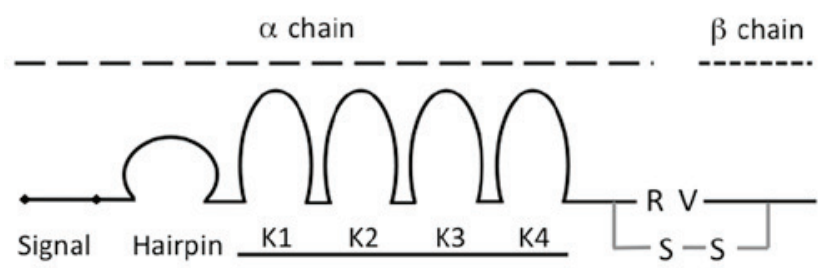

peptide loop Kringle $(\mathrm{K})$ domain

B

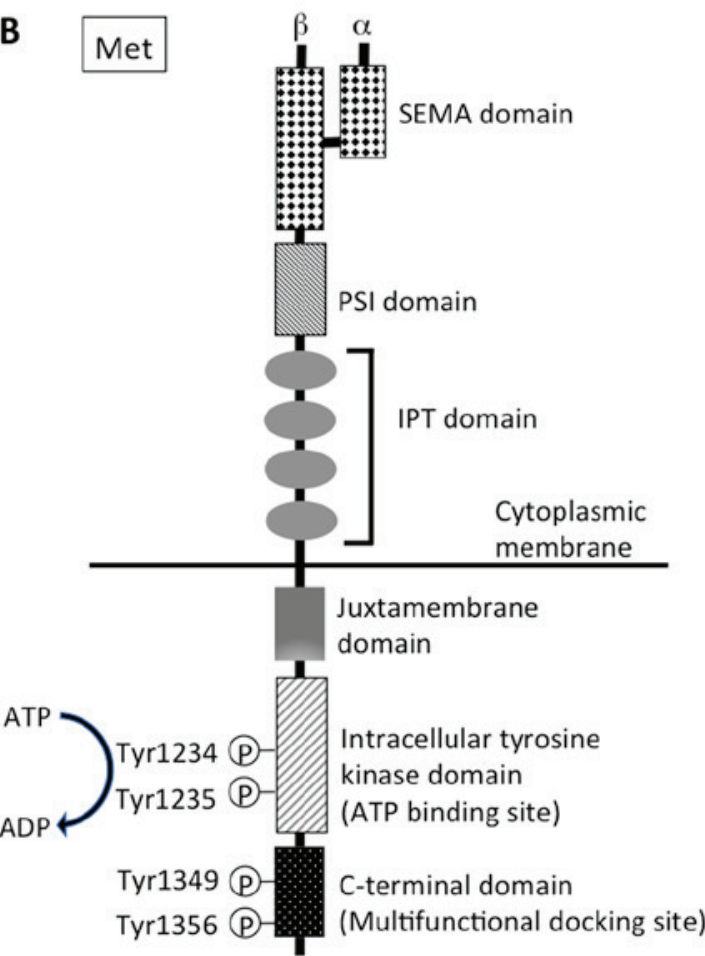

C

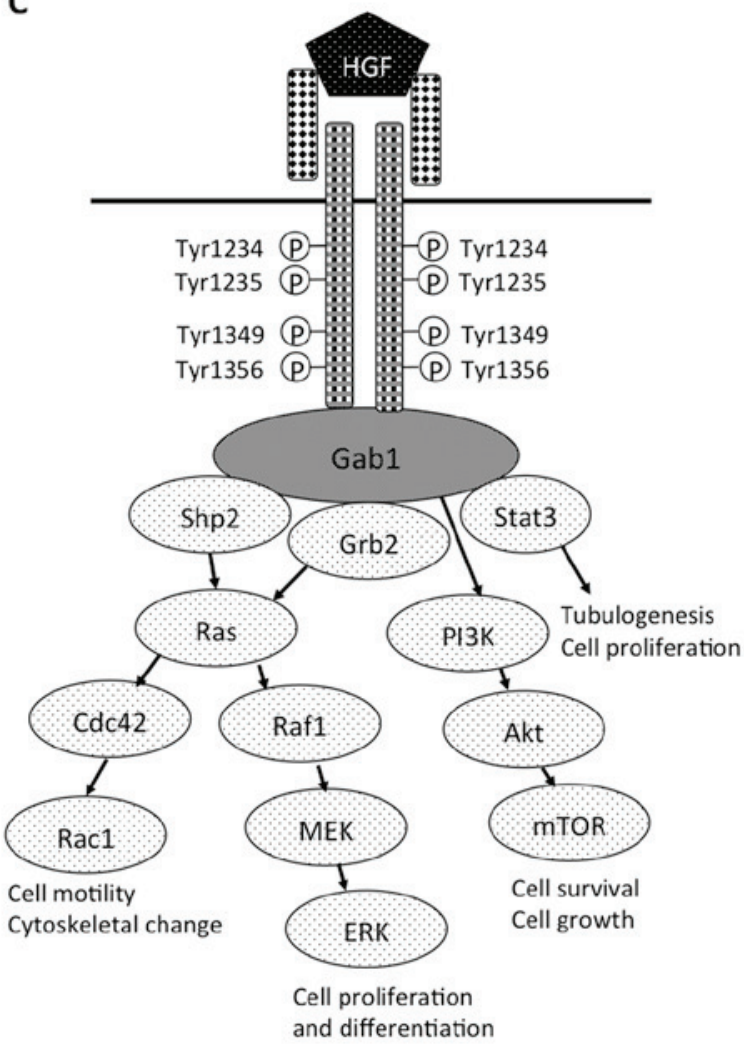

Figure 1. Structure of (A) HGF and (B) Met. (C) Downstream signaling pathway of HGF-Met signal. HGF, hepatocyte growth factor; R, arginine; V, valine; S-S, disulfide bond; SEMA, semaphorin; PSI, plexin, semaphorin, integrin cysteine-rich domain; IPT, immunoglobulin-like regions in plexins and transcription factors; Gab1, Grb2-associated protein 1; shp2, Src homology region 2 domain-containing phosphatase-2; Grb2, growth factor receptor-bound protein 2; Stat3, signal transducer and activation of transcription-3; PI3K, phosphoinositide 3-kinase; Cdc42, cell division control protein 42 homolog; Raf1, Raf-1 proto-oncogene, serine/threonine kinase; Rac1, Rac family small GTPase 1; MEK, mitogen-activated protein kinase kinase; mTOR, mechanistic target of rapamycin; ERK, extracellular signal-regulated kinases.

and was later purified to homogeneity from human plasma (14). Based on the amino acid sequence homology and biological activity in macrophages, Shimamoto et al (15) identified that HLP was identical to MSP (15). MSP/HLP has a $45 \%$ amino acid sequence similarity with HGF (12) and is characterized by kringle domains in the $\alpha$ chain, and a serine protease domain in the $\beta$ chain; however, it is devoid of enzymatic activity due to amino acid substitutions in the catalytic triad.

Met. The receptor for HGF was identified as a $c$-met protooncogene, which produces a transmembrane receptor tyrosine kinase $(16,17)$. MET is located at $7 \mathrm{q} 31$, which spans $>120 \mathrm{~kb}$ in length and consists of 21 exons (18). The MET receptor is a heterodimer, consisting of an extracellular $\alpha$-subunit (50 kDa) with the $\mathrm{N}$-terminal and $\beta$-subunit ( $140 \mathrm{kDa}$ ) that are linked by disulfide bonds. The Met $\beta$-subunit consists of a semaphorin domain (SEMA), a plexin, semaphorin, integrin cysteine-rich domain (PSI), four immunoglobulin-like domains, a transmembrane region, a juxtamembrane region, and an intracellular tyrosine kinase domain, and a C-terminal tail (Fig. 1B) $(19,20)$. HGF binds the SEMA domain, in which the MET-associated sequence resides. As a result of HGF-induced dimerization, the intracellular tyrosine kinase domains of the two receptor $\beta$-subunits trans-phosphorylate each other at residues Tyr1234 and Tyr1235 within the catalytic loops (21). An intracellular multisubstrate docking site, which is located near the C-terminal, contains tyrosine residues, Tyr1349 and Tyr1356 (22-24). Their subsequent phosphorylation recruits intracellular signaling molecules, including growth factor receptor-bound protein 2 (Grb2), Grb2-associated protein 1 (Gab1), phosphoinositide 3-kinase (PI3K), phospholipase C $\gamma 1$, $\mathrm{SH} 2$ containing protein tyrosine phosphatase and signal transducer and activation of transcription-3 (Stat3) (Fig. 1C).

Met activation induces various biological responses, including proliferation, motility, cell survival, morphogenesis and angiogenesis. All of these effects are consistent with their 
role in vivo. HGF and Met expression patterns indicate their importance in the formation and homeostasis of numerous tissues. At the early stages of development, HGF and Met exhibit expression in the mesoderm and endoderm, respectively, and may act in an autocrine fashion. During organogenesis, Met is detected in epithelial cells of many organs, such as the liver, kidney, lungs and skin.

The HGF-Met signal stimulates a wide range of different cellular signaling pathways and it is important for the control of tissue homeostasis under physiological conditions. Hypoxia activates Met transcription, resulting in higher expression levels of Met, and amplifies HGF signaling (25). However, a receptor protein-tyrosine phosphatase (PTP), density enhanced phosphatase-1 (DEP-1), has been implicated in the regulation of cell growth, differentiation and transformation, and has been identified as a potential tumor suppressor gene (26). As DEP-1 dephosphorylates particular tyrosine residues that are required for Met-induced signaling, DEP-1 may function in controlling the specificity of downstream signals (26). Furthermore, PTP1B knockout (KO) mice exhibit increased insulin sensitivity and resistance to weight gain, and are resistant to Fas-induced liver injury and lethality (27). The downregulation of Met involves ligand-induced internalization, ubiquitination by casitas B-lineage lymphoma ubiquitin ligases, and lysosomal degradation (28-30). A ubiquitination-deficient Met receptor mutant (Y1003F) is tumorigenic and this mutant is inefficiently targeted for degradation (29).

\section{HGF and Met KO mice}

The indispensable roles of the HGF-Met system in mammalian development have been elucidated by the targeted disruption of the $H G F$ and c-met genes. HGF KO mice were generated in previous studies $(2,30)$. The deletion was embryonically lethal; $\mathrm{HGF}^{-/-}$mice succumbed between embryonic day (E)13 and E16.5, and the mice also exhibited placental defects (31). In addition, the $c$-met $\mathrm{KO}$ mice were embryonically lethal between E13 and E16.5 (32). Furthermore, mutations of two phosphorylated tyrosines (Tyr1349 and Tyr1356) in the carboxy-terminal tail $\left(\mathrm{Met}^{\mathrm{D}}\right)$ lead to the failed coupling of the Met receptors to their effectors. Therefore, $\mathrm{Met}^{\mathrm{D} / \mathrm{D}}$ mice demonstrated embryonic death with placenta, liver and limb muscle defects (22), mimicking the phenotype of $c$-met null mutants.

\section{Conditional Met KO mice}

Numerous reports of conditional $\mathrm{KO}$ (cKO) mice have revealed that the HGF-Met system has developmental and regenerative effects at various epithelial sites in the immune system, including the liver, kidneys, lungs and neurons. Based upon these data, the common underlying mechanisms of the HGF-Met system for tissue repair in many organs are emphasized in the current study.

Methodology of the Cre-loxP system for Met deletion. This selective ablation system allows gene silencing of the $c$-met gene to be restricted to specific tissues and, in certain cases, to specific times during development or regeneration by simultaneous use of the Cre-loxP system simultaneously $(33,34)$. Inactivation of the mouse $c$-met gene was achieved by a conditional deletion of exon 16, which contains an ATP-binding site in the intracellular tyrosine kinase domain, essential for activation of the HGF-Met signaling pathway $(33,34)$. These 'floxed' c-met mice were mated with various $C r e$ recombinase transgenic mice, and conditional $c$-met $\mathrm{KO}\left(\mathrm{Met}^{-/-}\right.$; $\left.\mathrm{cKO}\right)$ mice have been broadly used to analyze the function of the HGF-Met signaling pathway in development or during the regeneration process (Table I).

Liver-specific Met deletion. Borowiak et al (33) reported that Cre expression was induced by interferon $-\gamma$ and complete recombination of the floxed allele occurred in the liver of $\mathrm{Mx}-\mathrm{Cre} ; \mathrm{Met}^{\mathrm{flox} /-}$ mice. The size of the liver in these mice was normal, and the histology was unchanged three weeks after recombination; however, after six months, many small lipid vesicles were observed in the livers. More marked hepatic changes were observed in these cKO mice during regeneration. Following partial hepatectomy $(\mathrm{PH})$, the size of the liver in conditional $\mathrm{Met}^{-/-}$mice was smaller, and the proliferating cell population was decreased by $60 \%$ when compared with that of the control mice. Regarding the cell cycle, the $\mathrm{Met}^{-{ }^{-}}$ livers exhibited a defective exit from quiescence and reduced entry into the $\mathrm{S}$ phase. Huh et al (34) reported that the adaptive responses of the liver to injury were markedly affected (34). These cKO mice were hypersensitive to Fas-induced apoptosis of hepatocytes. When injected with a low dose of anti-Fas antibody, wild-type mice survived with signs of minor injury, whereas almost all cKO mice succumbed due to massive apoptosis and hemorrhagic necrosis. In addition, subsequent to injection with a single necrogenic dose of chemokine (C-C motif) ligand 4, cKO mice exhibited impaired recovery rather than a deficit in hepatocyte proliferation (34). The delayed regeneration was associated with a persistent inflammatory reaction, the over-production of osteopontin, and early and prominent dystrophic calcification (34). These results revealed that the disruption of $c$-met primarily affects hepatocyte survival and tissue remodeling.

To address the role of $\mathrm{HGF}$ during the $\mathrm{G}_{2} / \mathrm{M}$ transition, Factor et al (35) evaluated the cell cycle following $\mathrm{PH}$ of $\mathrm{cKO}$ (Alb-Cre; $\mathrm{Met}^{\mathrm{f} / \mathrm{fl}}$ ) mice and identified that HGF has a novel function in the regulation of $\mathrm{G} 2 / \mathrm{M}$-associated gene expression (35). These cKO mice demonstrated defects in redox regulation, and thus the increased sensitivity to Fas-induced apoptosis and adaptive upregulation of $\mathrm{NF}-\kappa \mathrm{B}$ survival signaling (36). These cKO mice were fed a methionine-choline-deficient diet to imitate non-alcoholic-fatty liver disease, and this led to massive steatosis, decreased survival and higher transaminase levels in these mice (37). These findings demonstrate that the HGF-Met signaling pathway is directly involved in the proliferation and survival of hepatocytes.

Other functions of HGF have been reported in the liver. The loss of the HGF-Met signaling pathway in hepatocytes enhanced, rather than suppressed, the early stages of hepatocarcinogenesis (38). cKO mice treated with $\mathrm{N}$-nitrosodiethylamine developed significantly more tumors of a larger size, associated with the increased proliferation and enhanced activation of estimated glomerular filtration rate signaling. Focusing on the oval cells (hepatic stem cell progeny), the liver-specific $\mathrm{Met}^{-/-}$mice were subjected to chronic liver injury, which was induced by a diet containing a porphyrinogenic agent (39). 
Table I. Summarized phenotypes of conditional c-Met KO mice (Cre-LoxP system).

\begin{tabular}{|c|c|c|c|c|}
\hline Organ & Target cells & $\begin{array}{l}\text { Cre-expression } \\
\text { (gene promoter) }\end{array}$ & Summarized outcomes & (Refs.) \\
\hline \multirow[t]{3}{*}{ Liver } & $\begin{array}{l}\text { Hepatocytes } \\
\text { (oval cells) }\end{array}$ & Alb, Mx1, Alfp & $\begin{array}{l}\text { Increased liver damage and fibrosis. Impaired } \\
\text { liver regeneration. }\end{array}$ & $(33-39)$ \\
\hline & & & $\begin{array}{l}\text { Increase of apoptosis. Decrease of hepatocyte } \\
\text { migration and proliferation. }\end{array}$ & $(33-35)$ \\
\hline & & & $\begin{array}{l}\text { Defects in redox regulation. Failure of hepatic } \\
\text { stem cell mobilization. }\end{array}$ & $(36,39)$ \\
\hline \multirow[t]{3}{*}{ Kidney } & Tubular cells & $\begin{array}{l}\text { HoxB7 (collecting } \\
\text { duct), Ksp, } \\
\gamma \mathrm{GT} \text { (proximal) }\end{array}$ & $\begin{array}{l}\text { Reduction of uretic bud branching and } \\
\text { nephrons. Decreased kidney regeneration. }\end{array}$ & $(40,41)$ \\
\hline & & & $\begin{array}{l}\text { Increased interstitial fibrosis, tubular necrosis } \\
\text { and apoptosis. }\end{array}$ & $(40,41)$ \\
\hline & Podocytes & Podocin & Increased podocyte injury and proteinuria. & $(42)$ \\
\hline Lung & Alveolar type II cells & $\mathrm{SP}-\mathrm{C}$ & $\begin{array}{l}\text { Impaired airspace formation marked by reductions } \\
\text { in alveolar epithelial cell abundance and survival. }\end{array}$ & $(50,51)$ \\
\hline & & & Failure of the vascular system. & $(50,51)$ \\
\hline \multirow[t]{3}{*}{ Pancreas } & $\beta$-cells & RIP, Pdx & $\begin{array}{l}\text { Impairment of glucose tolerance and } \\
\text { glucose-dependent insulin secretion. }\end{array}$ & $(52,53)$ \\
\hline & & & $\begin{array}{l}\text { Incomplete maternal } \beta \text {-cell adaptation. Development } \\
\text { of gestational diabetes mellitus. }\end{array}$ & $(79)$ \\
\hline & & & $\begin{array}{l}\text { Sensitive to injuries and decrease of } \beta \text {-cell } \\
\text { regeneration. }\end{array}$ & $(54,55)$ \\
\hline Heart & Cardiomyocytes & $\alpha-\mathrm{MHC}$ & $\begin{array}{l}\text { Cardiomyocyte hypertrophy associated with } \\
\text { interstitial fibrosis and systolic cardiac dysfunction. }\end{array}$ & $(56)$ \\
\hline Breast & Mammary epithelium & MMTV & Defects in branching in mammary glands. & $(80)$ \\
\hline Skin & Keratinocytes & K14 & Reepitheliazation after skin wounding. & $(57)$ \\
\hline Muscle & Satellite cells & $\operatorname{Pax} 7$ & Defective muscle regeneration in response to injury. & $(81)$ \\
\hline Eye & $\begin{array}{l}\text { Retinal pigment } \\
\text { epithelium }\end{array}$ & AAV injection & $\begin{array}{l}\text { Reduction of retinal pigment epithelium migration } \\
\text { into the outer retina of laser-injured eyes. }\end{array}$ & $(82)$ \\
\hline \multirow[t]{3}{*}{ Neuron } & $\begin{array}{l}\text { Neurons in the } \\
\text { dorsal pallium }\end{array}$ & Emx1 & $\begin{array}{l}\text { Alteration of neuron architecture. Excitatory } \\
\text { hyperconnectivity and hypoactivity. }\end{array}$ & $(45-48)$ \\
\hline & All neural cells & Nestin & Deficit in contextual fear condition. & $(45)$ \\
\hline & $\begin{array}{l}\text { Myenteric plexus } \\
\text { neurons }\end{array}$ & Wnt1 & $\begin{array}{l}\text { Reduced length of neurites and increased } \\
\text { bowel injury. }\end{array}$ & $(49)$ \\
\hline \multirow[t]{3}{*}{ Immunity } & Dendritic cells & Mx1 & $\begin{array}{l}\text { Failure to emigrate toward lymph nodes during } \\
\text { inflammation. Impaired contact hypersensitivity } \\
\text { reaction. }\end{array}$ & $(83)$ \\
\hline & Neutrophils & Mrp8 & Increased tumor growth and metastasis. & $(43)$ \\
\hline & T-cells & CD4 & Acceleration of age-related thymic involution. & $(44)$ \\
\hline
\end{tabular}

KO, knockout; Alb, albumin; Mx1, MX dynamin-like GTPase 1; Alfp, alpha-fetoprotein; HoxB7, homeobox B7; Ksp, kidney-specific; $\gamma$ GT, $\gamma$-glutamyl transferase; SP-C, surfactant protein-C; RIP, rat insulin promoter; Pdx, pancreatic duodenal homeobox; $\alpha$-MHC, $\alpha$-myosin heavy chain; MMTV, mouse mammary tumor virus; K14, keratin 14; Pax7, paired box 7; AAV, adeno-associated virus; Emx1, empty spiracles homeobox 1; Mrp8, myeloid-related protein 8; CD4, cluster of differentiation 4.

The absence of Met caused severe hepatic degradation and prevented stem-cell-mediated liver regeneration; thus, HGF may also control liver regeneration via stem cells (39).

Kidney-specific Met deletion. In the kidneys, Met is expressed and HGF-Met signaling is important in renal tubular epithelial cells and visceral epithelial cells (podocytes). Ishibe et al (40) reported the selective loss of Met expression in the collecting system. The morphology of the collecting system was demonstrated to be almost normal, although a reduction in the number of nephrons and glomerular hypertrophy was observed (40). However, to address the role of HGF in the adult collecting 
ducts during renal injury, cKO mice (HoxB7-Cre;Met $\left.{ }^{\mathrm{t} / \mathrm{fl}}\right)$ were generated. In a model of nephron injury and fibrosis, increased interstitial fibrosis, inflammatory cell infiltration and acute tubular necrosis were noted in the tubular cell-specific $\mathrm{Met}^{-/-}$mice (41). Furthermore, these mice exhibited a reduced tubular cell proliferation and kidney regenerative capacity following release of the obstruction, thus leading to impaired functional recovery. Therefore, the HGF-Met signaling pathway in the collecting duct is a major regulator of cell survival and induction of the repair process.

Podocyte-specific $\mathrm{Met}^{-1-}$ mice were also generated in a previous study (42). Subsequent to adriamycin treatment, these $\mathrm{cKO}$ mice developed more marked podocyte injury and albuminuria.

Immune system-specific Met deletion. The HGF-Met system has become a focus of studies on immunity. Mutations or amplifications of Met are correlated with the pathogenesis of various types of tumor, and Met is expressed by cancer cells, as well as by tumor-associated stromal cells. The HGF-Met system is also required for neutrophil chemoattraction and cytotoxicity, and Met deletion in neutrophils enhances tumor growth and metastasis (43). This may be due to the reduced neutrophil infiltration of the primary tumors and the metastatic sites. Tumor-derived TNF- $\alpha$ or other inflammatory stimuli induce Met in neutrophils, and this is essential for neutrophil transmigration across the activated endothelium and for inducible nitric oxide synthase expression. Furthermore, nitric oxide release by HGF-stimulated neutrophils promotes cancer cell killing, which prevents tumor growth and metastasis.

Song et al (44) generated T cell-specific $\mathrm{Met}^{-/}$mice to investigate the role of the HGF-Met signaling pathway in thymocyte development and recovery (44). These mice were more sensitive to sub-lethal irradiation and dexamethasone treatment. The number of total thymocytes and their subsets was markedly reduced in T-cell-specific $\mathrm{Met}^{-/-}$mice, and the thymic architecture of 12-month-old T-cell-specific Met $^{-/ /}$mice was similar to that of the 20-month-old wild-types.

Neuron-specific Met deletion. The HGF-Met system regulates neuronal development, including neuronal growth and synapse development. A5' promoter polymorphism of $c$-met is correlated with an increased risk of autism spectrum disorder (ASD)(45), and Met expression levels are reduced in the postmortem temporal lobe of individuals with autism and Rett syndrome. Through human genetic analysis and murine neuroanatomical expression mapping, HGF-Met signaling was demonstrated to be involved in the development of forebrain circuits controlling social and emotional behaviors that are atypical in ASD (46). To clarify roles of the HGF-Met signaling pathway on forebrain circuit development, the cKO mice (Emx1-Cre;Met $\left.{ }^{\mathrm{f} \times / \mathrm{fx}}\right)$ with Met deletion in the dorsal pallium-derived forebrain neurons were investigated (46). Excitatory hyperconnectivity in specific neocortical microcircuits constitutes a basis for the Met-mediated ASD risk $(46,47)$. Consistent with the morphological and biochemical changes, cKO mice exhibited the precocious maturation of excitatory synapses, as indicated by a reduction in the proportion of silent synapses, a faster GluN2A subunit switch, and an enhanced acquisition of $\alpha$-amino-3-hydroxy-5-methyl-4-isoxazolepropionic acid receptors at synaptic sites (48). Mistimed maturation of glutamatergic synapses leads to aberrant neuronal circuits that may be associated with risk for ASD. Furthermore, to understand the impacts of Met on behavior, Thompson and Levitt (45) investigated two lines of cKO (Emx1-Cre; $\mathrm{Met}^{\mathrm{fx} / \mathrm{fx}}$ and Nestin-Cre; $\mathrm{Met}^{\mathrm{f} \times / \mathrm{fx}}$ ) mice in which Met was deleted from specific cell populations of the central nervous system. The Emx1-Cre; Met ${ }^{\mathrm{fx} / \mathrm{fx}}$ mice displayed significant hypoactivity in the activity chamber and a deficit in spontaneous alteration in the T-maze. Notably, neuron-specific cKO mice exhibited deficits in contextual fear conditioning (45). HGF-Met signaling therefore contributes to the development of circuits mediating social, emotional and cognitive behavior.

In addition, Met was localized to a subset of calcitonin gene-associated peptide-positive myenteric plexus neurons, which are intrinsic primary afferent neurons in the gut (49). Met deletion in myenteric plexus neurons demonstrated a marked loss and reduced length of myenteric plexus Met-immunoreactive neurites (49). These mice exhibited more bowel damage and reduced epithelial cell proliferation following dextran sodium sulfate treatment (49).

Lung-specific Met deletion. Pulmonary capillary development depends on epithelium-derived vascular endothelial growth factor (VEGF)-A (50), and HGF expression may be associated with septum formation. To investigate the essential roles of HGF, alveolar epithelial cell type II (AECII)-specific $\mathrm{Met}^{-1-}$ mice were generated (50). The cKO $\left(\mathrm{Met}^{--}\right)$lung displayed impaired saccular development and enlarged distal airspaces with few primary septae. Furthermore, to analyze the postnatal phenotype of these $\mathrm{cKO}$ mice using doxycycline, tri-transgenic mice were generated (51). The cKO mice exhibited markedly impaired airspace formation due to a reduction in AEC abundance and survival, truncation of the pulmonary vascular bed and enhanced oxidative stress in AECIIs (51). The HGF-Met signaling pathway therefore performs essential functions in lung development, particularly in septum formation.

Pancreatic $\beta$-cell-specific Met deletion. To examine the essential roles of the HGF-Met system in $\beta$-cells, Met was deleted using rat insulin II promoter (RIP)-driven Cre expression $(52,53)$. $\beta$-cell-specific Met ${ }^{-/ /}$mice exhibited normal body weight, blood glucose and plasma insulin levels $(52,53)$. However, the mice exhibited reduced glucose tolerance and reduced plasma insulin levels following glucose challenge; thus, the HGF-Met signaling pathway may be essential for normal glucose-dependent insulin secretion. In addition, cKO mice displayed markedly increased apoptosis and decreased proliferation following multiple low-dose streptozotocin treatments, and markedly reduced $\beta$-cell regeneration following pancreatectomy $(54,55)$.

Cardiac myocyte-specific Met deletion. To investigate the requirement of the HGF-Met signaling pathway in cardiomyocytes, Arechederra et al (56) generated mice with Met deletion in cardiomyocytes using the $\alpha$-myosin heavy chain (MHC)-Cre mouse line. These cKO mice developed cardiomyocyte hypertrophy and interstitial fibrosis. The mice displayed significant upregulation of markers of myocardial 
damage, such as $\alpha-\mathrm{MHC}$ and atrial natriuretic factor, and systolic cardiac dysfunction.

Skin-specific Met deletion. The skin has barrier functions for many forms of environmental stress, and therefore has an efficient system to repair wounds. At the wound edges, keratinocytes form a hyperproliferative epithelium (HE) that strongly proliferates and migrates to recover the wound area, and HGF and Met are upregulated in the HE during wound repair. Chmielowiec et al (57) analyzed the epidermis in cKO (K14-Cre; $\mathrm{Met}^{\mathrm{f} / \mathrm{fl}}$ ) mice (57). The reepithelialization of skin keratinocytes was impaired, wound closure was slightly attenuated in keratinocyte-specific $\mathrm{Met}^{-/-}$mice and the closure of a scratch wound occurred in the presence of only a few remaining Met-positive cells (57). Therefore, the HGF-Met signaling pathway is a fundamental regenerative process in the skin.

Specific inhibition of HGF-Met downstream signaling. Among the downstream signaling molecules, Gab1 is critical in HGF-dependent biological responses $(58,59)$. Gab1 is a scaffolding adaptor protein, and a direct and robust interaction of Gabl and Met is responsible for the various biological activities of HGF. The phosphorylation of C-terminal tyrosine residues in the docking site of Met recruits intracellular signaling molecules, including PI3K, Src, Grb2, Shc adaptor, and the multi-adaptor Gab1. To address the role of specific signaling pathways in the HGF-Met system in vivo, these multifunctional docking sites were converted into specific binding motifs for PI3K, Src or Grb2 $\left(\mathrm{Met}^{2 \mathrm{P}}, \mathrm{Met}^{2 \mathrm{~S}}\right.$ or $\mathrm{Met}^{2 \mathrm{G}}$ ) (60). All three Met mutants retained normal signaling, but recruited specific effectors differentially. $\mathrm{Met}^{2 \mathrm{G}}$ mice developed normally, but $\mathrm{Met}^{2 \mathrm{P}}$ and $\mathrm{Met}^{2 \mathrm{~S}}$ mice displayed different phenotypes and rescued of distinct tissues following loss-of-function (60). The partial rescue of myoblast migration was the only trait in common and it most likely resulted from the net contribution of residual Gab1-mediated Met signaling.

\section{HGF transgenic mice}

Liver-specific HGF overexpression. Transgenic mice with HGF overexpression (HGF-Tg) under the control of the metallothionein promoter exhibited an increased liver size and a marked increase of $2 \mathrm{~N}$ small hepatocytes (61). HGF-Tg mice made using the albumin promoter exhibit a lower expression level of HGF when compared with HGF-Tg mice made using the metallothionein promoter, with a smaller increase in liver size $(62,63)$. The overexpression of HGF exerts a protective effect against Fas-mediated hepatic apoptosis in HGF-Tg mice. Akt phosphorylation and B-cell lymphoma-extra large expression levels were increased in HGF-Tg mice before and after anti-Fas antibody injection (64). Activation of the microsomal triglyceride transfer protein and apolipoprotein B, accompanied by higher triglyceride levels in the serum were also observed in HGF transgenic mice (65).

Pancreas-specific HGF overexpression. HGF-Tg mice were used to investigate HGF functions in the pancreas. The islets of RIP-regulated HGF-Tg mice contain more insulin per $\beta$-cell, secrete more insulin in response to glucose, have higher steady-state glucose transporter 2 and glucokinase levels, and take up and metabolize glucose more effectively. Furthermore, HGF has positive effects on $\beta$-cell mitogenesis, glucose sensing, $\beta$-cell markers of differentiation and transplant survival (66). Insulin receptor substrate-2 (IRS2)-- mice develop diabetes due to insulin resistance and $\beta$-cell failure. After crossing HGF-Tg mice with IRS2 KO mice, the progeny exhibited significantly reduced hyperglycemia, compensatory hyperinsulinemia, improved glucose tolerance and increased glucose-stimulated insulin secretion in $\mathrm{Tg} / \mathrm{KO}$ islets. Additionally, $\beta$-cell proliferation and mass were increased, and the mortality rate was decreased $(67,68)$. HGF-Tg mice were relatively hypoglycemic in post-prandial and fasting states, and demonstrated a markedly attenuated response to the diabetogenic effects of streptozotocin (68).

Neuron-specific HGF overexpression. Amyotrophic lateral sclerosis (ALS) is an adult-onset neurodegenerative disease characterized by a progressive loss of motoneurons in the brain cortex and spinal cord. HGF overexpression in the nervous system attenuates motoneuron death and axonal degeneration. HGF overexpressing mice exhibit an extended life span in an ALS model (G93A mice) that overexpresses mutated $\mathrm{Cu}^{2+} / \mathrm{Zn}^{2+}$ superoxide dismutase. HGF alleviates the symptoms of ALS by direct neurotrophic effects on motoneurons and indirect effects on glial cells, possibly favoring a reduction in glutamatergic neurotoxicity (69). G93A/HGF-Tg mice demonstrated marked decreases in the numbers of microglia and reactive astrocytes, and an attenuation of the motoneuron loss. HGF overexpression prevented monocyte chemoattractant protein-1 induction, suppressed caspase activation, and increased expression of $\mathrm{X}$ chromosome-linked inhibition of apoptosis protein in the motoneurons of G93A mice (70).

Spinal and bulbar muscular atrophy (SBMA) is an inherited motor neuron disease in the brain stem and spinal cord, caused by the expansion of a polyglutamine tract in the androgen receptor (AR) protein, which diffusely accumulates as inclusions in nuclei. By crossing SBMA model mice expressing a mutated AR gene with HGF-Tg mice, Ding et al (71) demonstrated that the high level of HGF expression induced Akt phosphorylation and modestly ameliorated motor symptoms in an SBMA mouse model. HGF administration may provide a possible combination therapy with other disease-modifying therapeutic strategies in SBMA (71).

Notably, HGF overexpression in the central nervous system advances learning and memory performance (72). HGF upregulated N-methyl-D-aspartate receptor subunits, NR2A and NR2B, and normal nervous system plasticity (72).

Mammary gland-specific HGF overexpression. The expressions levels of HGF and Met are regulated during mouse mammary gland development. HGF-Tg mice exhibited a range of alterations in the architecture of virgin mouse mammary glands, including an enhancement of the ductal end bud size, and numbers and hyperplastic branching morphogenesis (73).

Kidney-, skin-, and muscle-specific HGF overexpression. Concerning the role of HGF in the kidneys, HGF-Tg mice with expression in the proximal tubules, under the direction of the $\gamma$-glutamyl transpeptidase-I promoter, were developed. 
HGF overexpression markedly protected kidneys from ischemia-induced acute renal failure (74).

By analyzing excisional wound sites in HGF-Tg mice under the metallothionein promoter, Toyoda et al (75) revealed that HGF enhanced granulation tissue accompanied by marked vascularization with the induction of VEGF (75).

Muscle-specific HGF-Tg (SK-HGF) mice did not exhibit altered plasma HGF levels. When HGF-Tg mice were fed a normal diet, these mice displayed similar levels in body weight and blood glucose, plasma triglycerides and plasma insulin levels, and glucose tolerance when compared with wild-types. Obese HGF-Tg mice recovered improved whole-body glucose tolerance. Thus, muscle-specific expression of HGF counteracts obesity-mediated muscle insulin resistance and glucose tolerance in mice (76).

\section{Conclusion}

Numerous studies have broadly examined biological functions of the HGF-Met signaling pathway. Various studies have demonstrated the crucial physiological roles and therapeutic potentials of HGF during fetal development and recovery from disease conditions, including acute and chronic tissue injury, and immunological and neurodegenerative diseases. The characterization of mice with cell/tissue-selective disruption of the $c$-met gene particularly elucidated the essential roles of the HGF-Met signaling pathway in proliferation, survival, morphogenesis, tissue development, regeneration and organ homeostasis. Furthermore, the examination of mice with organ-specific overexpression of HGF revealed the therapeutic potential of using HGF to treat various types of disease. It is hoped that this review leads to important discussion of HGF therapeutic strategies based upon scientific evidence.

\section{Acknowledgements}

The author would like to thank Dr Matsumoto for useful advice.

\section{References}

1. Nakamura T, Nishizawa T, Hagiya M, Seki T, Shimonishi M, Sugimura A, Tashiro K and Shimizu S: Molecular cloning and expression of human hepatocyte growth factor. Nature 342: 440-443, 1989

2. Miyazawa K, Tsubouchi H, Naka D, Takahashi K, Okigaki M, Arakaki N, Nakayama H, Hirono S, Sakiyama O, Takahashi K, et al: Molecular cloning and sequence analysis of cDNA for human hepatocyte growth factor. Biochem Biophys Res Commun 163: 967-973, 1989.

3. Stoker M, Gherardi E, Perryman M and Gray J: Scatter factor is a fibroblast-derived modulator of epithelial cell mobility. Nature 327: 239-242, 1987.

4. Zarnegar R, Petersen B, DeFrances MC and Michalopoulos G: Localization of hepatocyte growth factor (HGF) gene on human chromosome 7. Genomics 12: 147-150, 1992.

5. Fukuyama R, Ichijoh Y, Minoshima S, Kitamura N and Shimizu N: Regional localization of the hepatocyte growth factor (HGF) gene to human chromosome 7 band q21.1. Genomics 11: 410-415, 1991.

6. Seki T, Hagiya M, Shimonishi M, Nakamura T and Shimizu S: Organization of the human hepatocyte growth factor-encoding gene. Gene 102: 213-219, 1991.

7. Andermarcher E, Surani MA and Gherardi E: Co-expression of the HGF/SF and c-met genes during early mouse embryogenesis precedes reciprocal expression in adjacent tissues during organogenesis. Dev Genet 18: 254-266, 1996.
8. Matsumoto K, Funakoshi H, Takahashi H and Sakai K: HGF-Met pathway in regeneration and drug discovery. Biomedicines 2: 275-300, 2014

9. Fajardo-Puerta AB, Mato Prado M, Frampton AE and Jiao LR: Gene of the month: HGF. J Clin Pathol 69: 575-579, 2016.

10. Matsumoto K, Tajima H, Okazaki H and Nakamura T: Negative regulation of hepatocyte growth factor gene expression in human lung fibroblasts and leukemic cells by transforming growth factor-beta 1 and glucocorticoids. J Biol Chem 267: 24917-24920, 1992.

11. Harrison P, Bradley L and Bomford A: Mechanism of regulation of HGF/SF gene expression in fibroblasts by TGF-beta1. Biochem Biophys Res Commun 271: 203-211, 2000.

12. Han S, Stuart LA and Degen SJ: Characterization of the DNF15S2 locus on human chromosome 3: Identification of a gene coding for four kringle domains with homology to hepatocyte growth factor. Biochemistry 30: 9768-9780, 1991.

13. Leonard EJ and Skeel A: A serum protein that stimulates macrophage movement, chemotaxis and spreading. Exp Cell Res 102: 434-438, 1976

14. Skeel A, Yoshimura T, Showalter SD, Tanaka S, Appella E and Leonard EJ: Macrophage stimulating protein: Purification, partial amino acid sequence, and cellular activity. J Exp Med 173: 1227-1234, 1991.

15. Shimamoto A, Kimura T, Matsumoto $K$ and Nakamura $T$ : Hepatocyte growth factor-like protein is identical to macrophage stimulating protein. FEBS Lett 333: 61-66, 1993.

16. Bottaro DP, Rubin JS, Faletto DL, Chan AM, Kmiecik TE, Vande Woude GF and Aaronson SA: Identification of the hepatocyte growth factor receptor as the c-met proto-oncogene product. Science 251: 802-804, 1991

17. Naldini L, Vigna E, Narsimhan RP, Gaudino G, Zarnegar R, Michalopoulos GK and Comoglio PM: Hepatocyte growth factor (HGF) stimulates the tyrosine kinase activity of the receptor encoded by the proto-oncogene c-MET. Oncogene 6: 501-504, 1991.

18. Liu Y: The human hepatocyte growth factor receptor gene: Complete structural organization and promoter characterization. Gene 215: 159-169, 1998.

19. Niemann HH: Structural insights into Met receptor activation. Eur J Cell Biol 90: 972-981, 2011.

20. Stamos J, Lazarus RA, Yao X, Kirchhofer D and Wiesmann C: Crystal structure of the HGF beta-chain in complex with the Sema domain of the Met receptor. EMBO J 23: 2325-2335, 2004.

21. Rodrigues GA and Park M: Autophosphorylation modulates the kinase activity and oncogenic potential of the Met receptor tyrosine kinase. Oncogene 9: 2019-2027, 1994.

22. Maina F, Casagranda F, Audero E, Simeone A, Comoglio PM, Klein R and Ponzetto C: Uncoupling of Grb2 from the Met receptor in vivo reveals complex roles in muscle development. Cell 87: 531-542, 1996.

23. Ponzetto C, Bardelli A, Zhen Z, Maina F, dalla Zonca P, Giordano S, Graziani A, Panayotou G and Comoglio PM: A multifunctional docking site mediates signaling and transformation by the hepatocyte growth factor/scatter factor receptor family. Cell 77: 261-271, 1994.

24. Sachs M, Weidner KM, Brinkmann V, Walther I, Obermeier A, Ullrich A and Birchmeier W: Motogenic and morphogenic activity of epithelial receptor tyrosine kinases. J Cell Biol 133: 1095-1107, 1996.

25. Pennacchietti S, Michieli P, Galluzzo M, Mazzone M, Giordano S and Comoglio PM: Hypoxia promotes invasive growth by transcriptional activation of the met protooncogene. Cancer Cell 3: 347-361, 2003.

26. Palka HL, Park M and Tonks NK: Hepatocyte growth factor receptor tyrosine kinase met is a substrate of the receptor protein-tyrosine phosphatase DEP-1. J Biol Chem 278: 5728-5735, 2003

27. Sangwan V, Paliouras GN, Cheng A, Dubé N, Tremblay ML and Park M: Protein-tyrosine phosphatase 1B deficiency protects against Fas-induced hepatic failure. J Biol Chem 281: 221-228, 2006.

28. Peschard P and Park M: Escape from Cbl-mediated downregulation: A recurrent theme for oncogenic deregulation of receptor tyrosine kinases. Cancer Cell 3: 519-523, 2003.

29. Abella JV, Peschard P, Naujokas MA, Lin T, Saucier C, Urbé S and Park M: Met/hepatocyte growth factor receptor ubiquitination suppresses transformation and is required for Hrs phosphorylation. Mol Cell Biol 25: 9632-9645, 2005. 
30. Schmidt C, Bladt F, Goedecke S, Brinkmann V, Zschiesche W, Sharpe M, Gherardi E and Birchmeier C: Scatter factor/hepatocyte growth factor is essential for liver development. Nature 373: 699-702, 1995

31. Uehara Y, Minowa O, Mori C, Shiota K, Kuno J, Noda T and Kitamura N: Placental defect and embryonic lethality in mice lacking hepatocyte growth factor/scatter factor. Nature 373: $702-705,1995$.

32. Bladt F, Riethmacher D, Isenmann S, Aguzzi A and Birchmeier C: Essential role for the c-met receptor in the migration of myogenic precursor cells into the limb bud. Nature 376: 768-771, 1995.

33. Borowiak M, Garratt AN, Wüstefeld T, Strehle M, Trautwein C and Birchmeier C: Met provides essential signals for liver regeneration. Proc Natl Acad Sci USA 101: 10608-10613, 2004.

34. Huh CG, Factor VM, Sánchez A, Uchida K, Conner EA and Thorgeirsson SS: Hepatocyte growth factor/c-met signaling pathway is required for efficient liver regeneration and repair. Proc Natl Acad Sci USA 101: 4477-4482, 2004.

35. Factor VM, Seo D, Ishikawa T, Kaposi-Novak P, Marquardt JU, Andersen JB, Conner EA and Thorgeirsson SS: Loss of c-Met disrupts gene expression program required for $\mathrm{G} 2 / \mathrm{M}$ progression during liver regeneration in mice. PLoS One 5: e12739, 2010.

36. Gómez-Quiroz LE, Factor VM, Kaposi-Novak P, Coulouarn C, Conner EA and Thorgeirsson SS: Hepatocyte-specific c-Met deletion disrupts redox homeostasis and sensitizes to Fas-mediated apoptosis. J Biol Chem 283: 14581-14589, 2008.

37. Kroy DC, Schumacher F, Ramadori P, Hatting M, Bergheim I, Gassler N, Boekschoten MV, Müller M, Streetz KL and Trautwein C: Hepatocyte specific deletion of c-Met leads to the development of severe non-alcoholic steatohepatitis in mice. J Hepatol 61: 883-890, 2014.

38. Takami T, Kaposi-Novak P, Uchida K, Gomez-Quiroz LE, Conner EA, Factor VM and Thorgeirsson SS: Loss of hepatocyte growth factor/c-Met signaling pathway accelerates early stages of $\mathrm{N}$-nitrosodiethylamine induced hepatocarcinogenesis. Cancer Res 67: 9844-9851, 2007.

39. Ishikawa T, Factor VM, Marquardt JU, Raggi C, Seo D, Kitade M, Conner EA and Thorgeirsson SS: Hepatocyte growth factor/c-met signaling is required for stem-cell-mediated liver regeneration in mice. Hepatology 55: 1215-1226, 2012.

40. Ishibe S, Karihaloo A, Ma H, Zhang J, Marlier A, Mitobe M, Togawa A, Schmitt R, Czyczk J, Kashgarian M, et al: Met and the epidermal growth factor receptor act cooperatively to regulate final nephron number and maintain collecting duct morphology. Development 136: 337-345, 2009.

41. Ma H, Saenko M, Opuko A, Togawa A, Soda K, Marlier A, Moeckel GW, Cantley LG and Ishibe S: Deletion of the Met receptor in the collecting duct decreases renal repair following ureteral obstruction. Kidney Int 76: 868-876, 2009.

42. Dai C, Saleem MA, Holzman LB, Mathieson P and Liu Y: Hepatocyte growth factor signaling ameliorates podocyte injury and proteinuria. Kidney Int 77: 962-973, 2010.

43. Finisguerra V, Di Conza G, Di Matteo M, Serneels J, Costa S, Thompson AA, Wauters E, Walmsley S, Prenen H, Granot Z, et al: MET is required for the recruitment of anti-tumoural neutrophils. Nature 522: 349-353, 2015.

44. Song Y, Su M, Panchatsharam P, Rood D and Lai L: c-Met signalling is required for efficient postnatal thymic regeneration and repair. Immunology 144: 245-253, 2015.

45. Thompson BL and Levitt P: Complete or partial reduction of the Met receptor tyrosine kinase in distinct circuits differentially impacts mouse behavior. J Neurodev Disord 7: 35, 2015.

46. Judson MC, Eagleson KL, Wang L and Levitt P: Evidence of cell-nonautonomous changes in dendrite and dendritic spine morphology in the met-signaling-deficient mouse forebrain. J Comp Neurol 518: 4463-4478, 2010.

47. Qiu S, Anderson CT, Levitt P and Shepherd GM: Circuit-specific intracortical hyperconnectivity in mice with deletion of the autism-associated Met receptor tyrosine kinase. J Neurosci 31: 5855-5864, 2011

48. Qiu S, Lu Z and Levitt P: MET receptor tyrosine kinase controls dendritic complexity, spine morphogenesis, and glutamatergic synapse maturation in the hippocampus. J Neurosci 34: 16166-16179, 2014.

49. Avetisyan M, Wang H, Schill EM, Bery S, Grider JR, Hassell JA, Stappenbeck T and Heuckeroth RO: Hepatocyte growth factor and met support mouse enteric nervous system development, the peristaltic response, and intestinal epithelial proliferation in response to injury. J Neurosci 35: 11543-11558, 2015.
50. Yamamoto H, Yun EJ, Gerber HP, Ferrara N, Whitsett JA and Vu TH: Epithelial-vascular cross talk mediated by VEGF-A and HGF signaling directs primary septae formation during distal lung morphogenesis. Dev Biol 308: 44-53, 2007.

51. Calvi C, Podowski M, Lopez-Mercado A, Metzger S, Misono K, Malinina A, Dikeman D, Poonyagariyon H, Ynalvez L, Derakhshandeh R, et al: Hepatocyte growth factor, a determinant of airspace homeostasis in the murine lung. PLoS Genet 9: e1003228, 2013.

52. Roccisana J, Reddy V, Vasavada RC, Gonzalez-Pertusa JA, Magnuson MA and Garcia-Ocaña A: Targeted inactivation of hepatocyte growth factor receptor c-met in beta-cells leads to defective insulin secretion and GLUT-2 downregulation without alteration of beta-cell mass. Diabetes 54: 2090-2102, 2005.

53. Dai C, Huh CG, Thorgeirsson SS and Liu Y: Beta-cell-specific ablation of the hepatocyte growth factor receptor results in reduced islet size, impaired insulin secretion, and glucose intolerance. Am J Pathol 167: 429-436, 2005.

54. Mellado-Gil J, Rosa TC, Demirci C, Gonzalez-Pertusa JA, Velazquez-Garcia S, Ernst S, Valle S, Vasavada RC, Stewart AF, Alonso LC and Garcia-Ocaña A: Disruption of hepatocyte growth factor/c-Met signaling enhances pancreatic beta-cell death and accelerates the onset of diabetes. Diabetes 60: 525-536, 2011.

55. Alvarez-Perez JC, Ernst S, Demirci C, Casinelli GP, MelladoGil JM, Rausell-Palamos F, Vasavada RC and Garcia-Ocaña A: Hepatocyte growth factor/c-Met signaling is required for $\beta$-cell regeneration. Diabetes 63: 216-223, 2014.

56. Arechederra M, Carmona R, González-Nuñez M, GutiérrezUzquiza A, Bragado P, Cruz-González I, Cano E, Guerrero C, Sánchez A, López-Novoa JM, et al: Met signaling in cardiomyocytes is required for normal cardiac function in adult mice. Biochim Biophys Acta 1832: 2204-2215, 2013.

57. Chmielowiec J, Borowiak M, Morkel M, Stradal T, Munz B, Werner S, Wehland J, Birchmeier C and Birchmeier W: c-Met is essential for wound healing in the skin. J Cell Biol 177: 151-162, 2007.

58. Weidner KM, Di Cesare S, Sachs M, Brinkmann V, Behrens J and Birchmeier W: Interaction between Gab1 and the c-Met receptor tyrosine kinase is responsible for epithelial morphogenesis. Nature 384: 173-176, 1996.

59. Sachs M, Brohmann H, Zechner D, Müller T, Hülsken J, Walther I, Schaeper U, Birchmeier C and Birchmeier W: Essential role of Gab1 for signaling by the c-Met receptor in vivo. J Cell Biol 150: 1375-1384, 2000

60. Maina F, Panté G, Helmbacher F, Andres R, Porthin A, Davies AM, Ponzetto C and Klein R: Coupling Met to specific pathways results in distinct developmental outcomes. Mol Cell 7: 1293-1306, 2001

61. Sakata H, Takayama H, Sharp R, Rubin JS, Merlino G and LaRochelle WJ: Hepatocyte growth factor/scatter factor overexpression induces growth, abnormal development, and tumor formation in transgenic mouse livers. Cell Growth Differ 7: 1513-1523, 1996

62. Shiota G, Wang TC, Nakamura T and Schmidt EV: Hepatocyte growth factor in transgenic mice: Effects on hepatocyte growth, liver regeneration and gene expression. Hepatology 19: 962-972, 1994.

63. Di Renzo MF, Olivero M, Martone T, Maffe A, Maggiora P, Stefani AD, Valente G, Giordano S, Cortesina G and Comoglio PM: Somatic mutations of the MET oncogene are selected during metastatic spread of human HNSC carcinomas. Oncogene 19: 1547-1555, 2000.

64. Suzuki H, Toyoda M, Horiguchi N, Kakizaki S, Ohyama T, Takizawa D, Ichikawa T, Sato K, Takagi H and Mori M: Hepatocyte growth factor protects against Fas-mediated liver apoptosis in transgenic mice. Liver Int 29: 1562-1568, 2009.

65. Kosone T, Takagi H, Horiguchi N, Ariyama Y, Otsuka T, Sohara N, Kakizaki S, Sato K and Mori M: HGF ameliorates a high-fat diet-induced fatty liver. Am J Physiol Gastrointest Liver Physiol 293: G204-G210, 2007.

66. García-Ocaña A, Vasavada RC, Cebrian A, Reddy V, Takane KK, López-Talavera JC and Stewart AF: Transgenic overexpression of hepatocyte growth factor in the beta-cell markedly improves islet function and islet transplant outcomes in mice. Diabetes 50: 2752-2762, 2001.

67. Alvarez-Perez JC, Rosa TC, Casinelli GP, Valle SR, Lakshmipathi J, Rosselot C, Rausell-Palamos F, Vasavada RC and García-Ocaña A: Hepatocyte growth factor ameliorates hyperglycemia and corrects $\beta$-cell mass in IRS2-deficient mice. Mol Endocrinol 28: 2038-2048, 2014. 
68. Garcia-Ocaña A, Takane KK, Syed MA, Philbrick WM, Vasavada RC and Stewart AF: Hepatocyte growth factor overexpression in the islet of transgenic mice increases beta cell proliferation, enhances islet mass, and induces mild hypoglycemia. J Biol Chem 275: 1226-1232, 2000

69. Sun W, Funakoshi H and Nakamura T: Overexpression of HGF retards disease progression and prolongs life span in a transgenic mouse model of ALS. J Neurosci 22: 6537-6548, 2002.

70. Kadoyama K, Funakoshi H, Ohya W and Nakamura T: Hepatocyte growth factor (HGF) attenuates gliosis and motoneuronal degeneration in the brainstem motor nuclei of a transgenic mouse model of ALS. Neurosci Res 59: 446-456, 2007.

71. Ding Y, Adachi H, Katsuno M, Huang Z, Jiang YM, Kondo N, Iida M, Tohnai G, Nakatsuji H, Funakoshi H, et al: Overexpression of hepatocyte growth factor in SBMA model mice has an additive effect on combination therapy with castration. Biochem Biophys Res Commun 468: 677-683, 2015.

72. Kato T, Funakoshi H, Kadoyama K, Noma S, Kanai M, OhyaShimada W, Mizuno S, Doe N, Taniguchi T and Nakamura T: Hepatocyte growth factor overexpression in the nervous system enhances learning and memory performance in mice. J Neurosci Res 90: 1743-1755, 2012.

73. Yant J, Buluwela L, Niranjan B, Gusterson B and Kamalati T: In vivo effects of hepatocyte growth factor/scatter factor on mouse mammary gland development. Exp Cell Res 241: 476-481, 1998.

74. Fiaschi-Taesch NM, Santos S, Reddy V, Van Why SK, Philbrick WF, Ortega A, Esbrit P, Orloff JJ and Garcia-Ocaña A: Prevention of acute ischemic renal failure by targeted delivery of growth factors to the proximal tubule in transgenic mice: The efficacy of parathyroid hormone-related protein and hepatocyte growth factor J Am Soc Nephrol 15: 112-125, 2004

75. Toyoda M, Takayama H, Horiguchi N, Otsuka T, Fukusato T, Merlino G, Takagi $\mathrm{H}$ and Mori M: Overexpression of hepatocyte growth factor/scatter factor promotes vascularization and granulation tissue formation in vivo. FEBS Lett 509: 95-100, 2001
76. Sanchez-Encinales V, Cozar-Castellano I, Garcia-Ocaña A and Perdomo G: Targeted delivery of HGF to the skeletal muscle improves glucose homeostasis in diet-induced obese mice. J Physiol Biochem 71: 795-805, 2015.

77. Zhou D, Tan RJ, Lin L, Zhou L and Liu Y: Activation of hepatocyte growth factor receptor, c-met, in renal tubules is required for renoprotection after acute kidney injury. Kidney Int 84 : 509-520, 2013

78. Mason S, Hader C, Marlier A, Moeckel G and Cantley LG: Met activation is required for early cytoprotection after ischemic kidney injury. J Am Soc Nephrol 25: 329-337, 2014.

79. Demirci C, Ernst S, Alvarez-Perez JC, Rosa T, Valle S, Shridhar V, Casinelli GP, Alonso LC, Vasavada RC and García-Ocana A: Loss of $\mathrm{HGF} / \mathrm{c}-\mathrm{Met}$ signaling in pancreatic $\beta$-cells leads to incomplete maternal $\beta$-cell adaptation and gestational diabetes mellitus. Diabetes 61: 1143-1152, 2012

80. Garner OB, Bush KT, Nigam KB, Yamaguchi Y, Xu D, Esko JD and Nigam SK: Stage-dependent regulation of mammary ductal branching by heparan sulfate and HGF-cMet signaling. Dev Biol 355: 394-403, 2011.

81. Webster MT and Fan CM: c-MET regulates myoblast motility and myocyte fusion during adult skeletal muscle regeneration. PLoS One 8: e81757, 2013.

82. Kasaoka M, Ma J and Lashkari K: c-Met modulates RPE migratory response to laser-induced retinal injury. PLoS One 7: e40771, 2012.

83. Baek JH, Birchmeier C, Zenke M and Hieronymus T: The HGF receptor/Met tyrosine kinase is a key regulator of dendritic cell migration in skin immunity. J Immunol 189: 1699-1707, 2012. 